\title{
Lusioersily
}

\section{Who do they think they are? Undergraduate perceptions of the definition of supernumerary status and how it works in practice}

McGowan, B. (2005). Who do they think they are? Undergraduate perceptions of the definition of supernumerary status and how it works in practice. Journal of Clinical Nursing, 15(9), 1099-1105. https://doi.org/10.1111/j.13652702.2005.01478.x

Link to publication record in Ulster University Research Portal

Published in:

Journal of Clinical Nursing

Publication Status:

Published (in print/issue): 02/09/2005

DOI:

10.1111/j.1365-2702.2005.01478.x

\section{Document Version}

Publisher's PDF, also known as Version of record

\section{General rights}

Copyright for the publications made accessible via Ulster University's Research Portal is retained by the author(s) and / or other copyright owners and it is a condition of accessing these publications that users recognise and abide by the legal requirements associated with these rights.

\section{Take down policy}

The Research Portal is Ulster University's institutional repository that provides access to Ulster's research outputs. Every effort has been made to ensure that content in the Research Portal does not infringe any person's rights, or applicable UK laws. If you discover content in the Research Portal that you believe breaches copyright or violates any law, please contact pure-support@ulster.ac.uk. 


\title{
Who do they think they are? Undergraduate perceptions of the definition of supernumerary status and how it works in practice
}

\author{
Brian McGowan BSc (Hons), MSc, PGDip, RN \\ Lecturer, School of Nursing, University of Ulster, Jordanstown, UK
}

Submitted for publication: 8 July 2005

Accepted for publication: 2 September 2005

\author{
Correspondence: \\ Brian McGowan \\ School of Nursing \\ University of Ulster \\ Jordanstown BT37OQB \\ UK \\ Telephone: 02890366492 \\ E-mail: brian.mcgowan@ulster.ac.uk
}

BRIAN MCGOWAN (2006) Journal of Clinical Nursing 15, 1099-1105

Who do they think they are? Undergraduate perceptions of the definition, of supernumerary status and how it works in practice

Aims and objectives. The aim of this study was threefold and was based on three research questions; how did students define supernumerary status, how was it implemented in practice and what effect did it have on them?

Background. Whilst there has been much debate about supernumerary status and its value to nursing practice and education there has been little work carried out from the student's point of view.

Design. The study was qualitative in nature.

Methods. Focus group interviews were the method of choice based on the premise that the interaction between students/participants would generate rich experiential data.

Results. Nine themes were generated that addressed the three questions asked. The themes to emerge from the category definition of supernumerary status were: not counted in the staff numbers and lack of student preparation. The themes to emerge from the category implementation of supernumerary status were: leadership style, experiences of mentorship, an extra pair of hands and not allowed to study. The themes to emerge from the category effect of supernumerary status were: their learning was enhanced, feelings of being used and reduction in self-confidence.

Conclusions. There is a need to review what is meant or indeed expected from students who are supernumerary and increased clarity is required about what it is supposed to achieve.

Relevance to clinical practice. The status of student nurses in practice has a direct link to the quality of the work they produce. This has a domino effect that may have far reaching consequences. Making sure that they are clear about what is expected of them from the outset will reduce confusion and allow them to move forward with skills acquisition and building their experience.

Key words: focus groups, nurse education, nurses, nursing, supernumerary status, undergraduate student nurses

\section{Introduction}

Much has been written about the concept of supernumerary status and its usefulness to nursing has been extensively debated. However, throughout all, the perceptions of student nurses appear to have been downplayed or even dismissed (Bradshaw 2001).
This paper reports the outcomes of a study funded by the Learning \& Teaching Support Network (LTSN) now under the auspices of the Higher Education Academy. The Higher Education Academy is an independent UK support body that has a triple focus. This focus is institutional support, i.e. supporting institutions in research and development that affects student learning. Subject and staff development and 
the provision of informed advice that influences policy making with regard to student learning. The study was based on three research questions that were designed to work out how student nurses defined supernumerary status in practice, how they felt it worked and what effect it had on them. The questions were:

- What did participants understand by the term supernumerary status?

- How supernumerary status was implemented on the placement wards?

- What effect did supernumerary status have on the participants involved?

Supernumerary status may be defined as the process by which essential practical nursing skills are developed in a supportive learning environment facilitated by an experienced member of nursing staff. This model of supernumerary status and mentorship is predicated on the assumption that a one-to-one relationship facilitates learning and socialization into the nurse's role (Patton \& Cook 1994).

\section{Literature review}

Whilst literature exists about the concept of supernumerary status, little research has been carried out from the students' perspective. The amount of literature dealing specifically with students and supernumerary status was small and issues that emerged are reported below.

From the outset Watson and Norrie (1997) argued that supernumerary status was never straightforward to define, understand or implement. They pointed out that there appeared to have been a fundamental bifurcation in the interpretation of supernumerary status with the General Nursing Council and Royal College of Nursing espousing conflicting views that echoed an underlying struggle between academia and service.

Ormerod and Murphy (1994) pointed out that the purpose of supernumerary status was to facilitate status shift (from worker to learner) for the student population and it was envisaged that the tasks that they would leave behind could be picked up by auxiliary nurses or health care assistants. However, making students supernumerary to spare them from being used as pairs of hands led (in some cases) to a situation were they were missing out on some fundamental nursing experiences and ran the risk of being excluded from the team. This view was supported by Downes (2001) who unambiguously declared that supernumerary status was one of the key elements that contributed to student nurse's perceived and actual lack of clinical skill. She further commented that mentors, acutely aware of their responsibility for student actions, may have been responsible for curtailing students practice arising from a misplaced fear of being accused of irresponsibility or demonstrating their inability to judge a students capability before assigning or allowing a task to be carried out. This would be especially relevant in a profession that values overt judgement skills as one its central tenets.

Spouse's (2000) study explored student nurses beliefs about how they would practice nursing. She found that with effective supernumerary status and mentorship students had a positive experience of nursing practice. Hyde and Brady (2002) found that following the implementation of supernumerary status in Ireland, supernumerary student nurses upset the ambient social structure and animosity arose from staff nurses because of an inability to easily pigeon hole the 'new' students.

White (1993) found that supernumerary status was understood by qualified staff but was rejected when staffing levels fell. This position was underlined by Endacott et al. (2003) who stated that despite being implemented to ensure that student learning needs were of paramount importance managers did not necessarily subscribe to this and would suppress learning needs in favour of service needs every time.

Ultimately, Castledine (2001) summed up the position well when he said, 'whatever new strategies are used one thing should be made clear: student nurses supernumerary status means that students must still get involved in practice so that they can realise not only their own needs but also their professional responsibilities.

\section{Method}

The data collection method used was focus group interview using a semi-structured interview schedule. Robinson (1999), p. 905) defined focus groups as, 'an in-depth, open-ended group discussion that explores a specific set of issues on a predefined and limited topic'. Ten focus groups were conducted in September-October 2003. The groups were digitally recorded, transcribed verbatim and this enabled themes to be identified using steps outlined by Morse and Field (1996).

All the participants $(n=60)$ who took part were secondyear students studying towards a BSc/BSc (Hons) in Nursing. First year students were intentionally excluded from the study because when the study took place they had not been in clinical practice and therefore had no direct experience of supernumerary status. Third years were unable to be included in the study because they were on placement at the time and access became problematic.

To ensure rigour throughout the study, the development of the research tool (focus group schedule) was commented on and revised by the advisory group, an audit trail was generated and the transcripts were concurrently analyzed by 
the research supervisor/project manager. This process reduced the potential for misinterpretation through offering opportunities for discussion that highlighted gaps in the analysis (Cutcliffe \& McKenna 1999).

Permission to carry out the study was sought from the local research ethics committee. Consent was obtained from all of the participants prior to taking part in the study and information and assurances were given to participants regarding their rights as research subjects.

\section{Findings and discussion}

In response to the first question (What did participants understand by the term supernumerary status?) the key theme to emerge was: Extra or not counted in the staff numbers on the ward. This involved ideas of being above and beyond what was necessary to safely staff a ward. This was a consistent interpretation amongst the participants highlighted by participants who said:

To me, it is going into to learn on placement and not being counted in as staff. You are there to watch and observe. You are there as an extra. [Group 6]

I was out on placement and the auxiliary was coming up to her holidays. She turned around to the sister and said put the student nurse on the days I'm not on and she [ward sister] actually gave me a list of things to do as an auxiliary just going around and doing them. There were days I was coming home saying why am I bothering (with a degree) I could go ahead and be an auxiliary without having to do all this (study). [Group 8]

It was interesting to note that the issue of observation only arose in the definition of supernumerary status. This raised a question about a fundamental misunderstanding on the participant's part before they went into practice. As a result, one could argue that this position could lead to feelings of frustration for the student when they were asked to do things they interpreted as being outside their remit. However, Parahoo (1992a) argued that participants did understand what supernumerary status meant but that this did not necessarily translate into practice.

The reality for many participants in the sample however was that they were counted on, which was illustrated by one participant who said:

You are not meant to make up the numbers but most times you were included in them. [Group 6]

The second theme to emerge from this section was that there appeared to be a degree of confusion about what was expected of participants when they were supernumerary and was labelled, lack of student preparation about supernumerary status. This was evidenced by participants referring to being there as observers or misinterpreting what being involved in the workload meant as illustrated in the above quotes but is best summed up by the participant who said:

I didn't know what I was entitled to or what my duty was. I wish somebody would have said 'this is supernumerary, this is what you do. [Group 2]

In response to the second question; how was supernumerary status implemented on clinical placement? The participant's interpretation of supernumerary status led them to clearly dichotomise when they were considered supernumerary on placement and when they were not. The participants also made it clear that this varied between wards.

The main theme to emerge from the data was labelled, leadership style. A number of participants' commented that the management approach on the ward (especially the sister's attitude/style) to supernumerary status was critical to its implementation. Where sister led the staff were sure to follow. This was highlighted by participants who described positive placement experiences:

Because that was the policy of the sister on the ward that you were there as a student and you were there to learn. [Group 6]

I think it is more to do with the sister. It is not really your individual mentor. [Group 8]

The importance of the attitude and experience of the ward sister about the outcome of a supernumerary placement has support in the literature. Yassin (1994) found that ward sister influence was important in how concepts were understood and applied at a local level. Similarly Parahoo (1992b) found that almost three quarters of his student sample expressed the opinion that implementation of supernumerary status was dependant upon the direction of the sister/charge nurse. This has clear implications regarding the focus of nurse preparation for supernumerary mentorship. It also is important to examine the factors behind the variation in approach within staff nurses.

Closely allied with leadership style was the theme labelled experiences of mentorship. It emerged from the data that participants felt that clinical staff were unprepared for their mentorship role and mentorship boiled down to how the individual adapted. Indeed participants rated some mentors without training highly. This theme was illustrated by the following statements:

It's very mixed. Some of them had done a pre-mentorship course before and some of them had never done the course and didn't think 
they could actually be a mentor but were allocated to be one. They were very much thrown in at the deep end and just went with it. Some of them were very good. It's a very individual thing. [Group 1]

My mentor in *****, she was very good in everything she did and she explained the reason's for doing it but as for the portfolio it was nonexistent. I think that was because she wasn't aware of what she was supposed to be helping. [Group 5]

Participants commented much more frequently however about poor mentorship and in particular the fact that the mentors were not prepared and did not conduct their supervision in a structured and consistent manner. This was illustrated by participants who said:

I don't think the mentors are prepared adequately enough to supervise the student nurse. [Group 5]

Depending on where I was again. For instance, I was in a placement in $* * * *$ and they had no idea as a mentor what we were supposed to be doing. However, they never had any mentorship training. They were just picked out of a crowd and were assigned certain participants. In the hospital environment they tend to have mentorship training but even then it depends on the mentor themselves to keep themselves up to date. [Group 9]

The reality appeared to be that most participants reported having multiple mentors on an ad hoc basis over the course of a placement with a large number of participants stating they had no one to one mentor for significantly long periods in their placement as illustrated by the following extracts:

It was three weeks before I even saw the whites of my mentor's eyes and I was there for six weeks. I worked seven full days with my mentor on the six weeks I was there. I wasn't allocated to anyone else. I just tagged along with whoever would take me. [Group 5]

I had three weeks on $* * * *$ and I had my mentor from Monday to Friday and then she went away on two weeks holidays and I had absolutely nobody for the remainder. [Group 9]

The main factors behind this ad hoc mentoring approach included problems matching the mentor and student on the ward rota together and wards' being short-staffed. The change in workforce patterns especially the increase in parttime staff and the degree to which staff can opt out of mentorship may also be a contributory factor. However more research would need to be carried out before further conclusions could be drawn. The heavy work demands on staff allowed the mentors little time to spend supervising the student. The following comments from participants' highlighted these important drawbacks:
In $* * *$, the staff felt that if it wasn't for the participants they wouldn't be able to cope with the work. [Group 5]

It was just a busy, busy place and it was so short-staffed as well. They [nurses] depended on us [participants] to do an awful lot of work and help out the auxiliaries. [Group 10]

Participants preferred the conventional one to one mentor/ student approach but some participants expressed approval for multiple mentoring. Quite often, this was the case when other staff were more effective in their teaching than the appointed mentor. This was captured by on participant who said:

I learnt loads from other nurses rather than my mentor. [Group 8]

Participants reported encountering an ad hoc multiple mentoring system much more often on placement. This has been a consistent finding in the literature. McGowan and McCormack (2003) reported that allocation to a mentor was a paper exercise in a number of cases with the student rarely working with their mentor stated that the situation of a student not working with a supervisor was also common situation.

It was clear however that participant's outlined instances of when they were not treated as supernumerary much more often than when they were. The main theme that encapsulated not being supernumerary was the participants' view that learning opportunities were compromised in order to meet service demands, that is they felt like an extra pair of hands.

This was borne out by many statements describing most of their time spent doing basic observations and auxiliary type work such as bed-making, making tea and the perception that they provided cover for staff holidays and sick leave. This was exemplified in the following comments:

One nurse actually said to me 'its great to get participants to do all the bed making and all the observation's. [Group 1]

That just about says it all. Just as long as you don't ask for anything above those skills. They didn't make me feel like a nuisance when I was doing useful work like bed-making or general stuff. I was being a nuisance when I wanted to improve my skills. [Group 1]

There is support in the literature for the contention that participants are viewed as an extra pair of hands after the manner of the traditional apprentice nurse model. Demands on limited staff have been pointed out as the main contributory reasons for participants learning aims being overruled by emphasis on helping out with manual tasks. (Phillips et al. 2000, Burkitt et al. 2001, Scholes \& Endacott 2002, Endacott et al. 2003). Questions arise as to the role of 
a supernumerary student on placement and this relates back to the participants narrow definition of supernumerary status as not being considered part of the workforce. Certainly, in cases where learning was considerably undermined on placement through constant emphasis on doing basic menial tasks, participants reported less satisfaction with their career choice. However, it should be asked is the student taking the observer role too far in some instances?

The next theme to emerge was labelled, not allowed to study. Participants claimed that studying on the ward was discouraged in those placements where participants believed their supernumerary status was compromised. No study hours were allocated on placement and the problem was illustrated in comments such as the following:

During surgical we had a workbook to do. When our lecturer came down to see all the new participants one girl said that her mentor told her not to be doing that on the surgical ward. That was for homework. [Group 10]

In the last $* * *$ placement we weren't allowed to open our folders at all when we were on the ward or leaving the ward to go anywhere the library or anything. We had to work. [Group 1]

Participants felt they were viewed with suspicion by the ward staff when attempting to study on the ward. They felt that studying on the ward was regarded as the same as not doing any work. This is described in the following comments:

There seems to be a general consensus on the ward that if you are sitting down, you are not doing anything. You know if you are sitting in the office or whatever looking through ward manuals or anything, you are not actually working - you know 'you are skiving type of thing'. [Group 3]

My mentor said I shouldn't be doing academic stuff on the ward that I was given practical experience and it was based on my time on the ward. She sort of galled me about sitting because I was sitting when they were putting up surgical equipment, you know taking notes and stuff, and she criticised me for doing that. [Group 4]

A Swedish study by Öhrling and Hallberg (2000) revealed that 'creating space for learning' functioned as the basis of an ongoing process of mentoring and, in turn, of learning. They indicated that student learning functions as a medium between theory and practice and found participants put a high value on reflection and pointed out that this made demands on all those involved in nurse education to find ways and means to increase the amount of time and peace needed for reflection. Interestingly, their findings also indicated that participants need to be prepared on how to extract better learning from reflective practice. This issue was made more difficult for the participants because of service demands in the shape of long hours and weekend shifts.

The third question asked was; what effect did supernumerary status have on the participants involved? In response to this participants reported positive and negative effects of supernumerary status on their practice.

\section{Positive effect}

On placements where the participant's were considered supernumerary, the experience was reported as being very enjoyable and this theme was labelled their learning was enhanced. One participant described her experience as follows:

In my first placement I had an absolutely brilliant time in the $* * * *$. I was totally supernumerary. They had enthusiasm for me - all the staff. They were all wanting to teach me things. It was absolutely fantastic. [Group 5]

In one of my placements I was treated as a student who was there to learn. It was brilliant because I picked up so much because I wasn't counted as staff. There was enough staff there to cover the daily work and the nurses themselves weren't stressed and had time to explain to you exactly what was going on. You know explain things like drugs, what happens to patients, how you should behave around patients. Things you generally need to know. [Group 6]

Supportive, enthusiastic and friendly staff were identified as the key features of positive supernumerary status for the participants in this study. This was corroborated by Neary (1997a,b) who found that participants identified good mentors as those who made them feel part of the ward team. They also reported that an appreciation of the students needs in relation to their professional development was needed to be a good mentor.

\section{Negative effect}

On placements where the participants considered they were not treated as supernumerary they expressed feelings that they were being used to carry out the workload on the ward only. This theme was described as feelings of being used. Many participants described their time spent on the ward as carrying out auxiliary type work exclusively as illustrated by this comment:

It's not that you mind doing the work. I mean you wouldn't look down - it's not that there is anything wrong with auxiliary work but if you were getting to do the other stuff as well instead of just making beds and making tea and that. I mean I still haven't given an injection. If you got to do that on top of the other stuff it would be OK I think. [Group 3] 
They described exhausting workloads, long shifts and the detrimental effect this had on their study. One participant encapsulated this in the following extract:

There was one time I worked ten days before I got a day off. One day you would have been working 12 hours, the next day you would have been on in the morning and off in the afternoon, the next day in for 4 hours in the afternoon. It was chaotic. There was one week I worked four full days in a row. Four 12-hour shifts and I was shattered. Then I worked three night duty shifts one after the other which the staff don't even do. I was totally exhausted. You are the working horse on the ward and you are so tired when you go home that you don't want to study. [Group 5]

When participants felt their supernumerary status was seriously compromised, they described the negative effect this had on their self-confidence and self-esteem. This theme was labelled reduction in self-confidence. The following comments indicate such effects:

My confidence was shattered because of the inconsistency of what we were doing. I really felt that I learned less while I was there. [Group 5]

I think it breaks your confidence. [Group 10]

I think it actually knocks your confidence. [Group 7]

Comment was made about the detrimental effect of not having a clear mentorship model and the impact this had on student assessment. This theme was labelled disillusionment. Participants felt undervalued when a mentor who was not with them over long periods of their placement assessed their skill levels. This is typified in the following comments:

Assessments are hard because if you haven't spent your time with one nurse then they don't really know what you can do and what you are capable of and they are giving you a mark and they don't really know why they are giving you it. [Group 3]

That's all your portfolio is. Something that has to be signed for when the lecturer comes in and that's it like. [Group 8]

All of this has a detrimental effect on participants' selfesteem and self-confidence and flies in the face of the objectives of supernumerary status that was designed to create situations that enhanced a feeling of belonging and thus, confidence and esteem.

\section{Conclusion and implications for practice}

Overall this study generated nine themes. Participants appeared to be generally well disposed towards supernumerary status but an underlying lack of preparation and explanation of the concept led to inconsistent experiences of it. Armed with this misunderstanding the participants invariably suffered from disappointment and disillusionment in practice. Experiences in practice indicated a fundamental reliance on direction from others. It could be argued that this demonstrated the fundamental difference between the university ethos of independent thought and autonomy vs. practice's requirement for homogenization and compliance.

The implementation of the concept depended upon the leadership style of the ward manager and the extent to which mentors had been prepared and motivated. Overall the participants reported positive experiences of supernumerary status but were unable to clarify the components of what this was. They were more vociferous when describing negative experiences. When badly implemented and/or supported, supernumerary status has the effect of eroding student nurses confidence to practice and enthusiasm/motivation for their profession. The extent to which this affects the quality of care being delivered to patients remains to be explored.

There are a number of implications for practice arising from this report and may be listed as:

- An urgent need to clarify the definition of supernumerary status and communicate this to student nurses before they go out on clinical placements.

- A review of the processes by which institutions prepare students for supernumerary status.

- An examination of the preparation and role of mentors/ mentorship.

- A need to examine models of mentorship.

- A need to investigate mentors perceptions of supernumerary status.

- An examination of the organisational factors that support and impede the implementation of supernumerary status.

\section{Contributions}

Study design: BM; data collection and analysis: BM; manuscript preparation: $\mathrm{BM}$

\section{References}

Bradshaw A (2001) The Project 2000 Nurse. Whurr, London. Burkitt I, Husband C, Mackenzie J, Torn A \& Crow R (2001) Nurse Education and Communities of Practice. Researching Professional Education Series no. 18. ENB, London.

Castledine G (2001) The problems of student supernumerary status. British Journal of Nursing 10, 626.

Cutcliffe JR \& McKenna HP (1999) Establishing the credibility of qualitative research findings: the plot thickens. Journal of Advanced Nursing 30, 374-380.

Downes M (2001) Support for student training: a new role as demonstrators. Nursing Times 97, 39. 
Endacott R, Scholes J, Freeman M \& Cooper S (2003) The reality of clinical learning in critical care settings: a practitioner-student gap? Journal of Clinical Nursing 12, 778-785.

Hyde A \& Brady D (2002) Staff nurses perceptions of supernumerary status compared with rostered service for Diploma in Nursing students. Journal of Advanced Nursing 38, 624632.

McGowan B \& McCormack B (2003) Supernumerary status: definition, operationalisation and its effect in practice. Intensive and Critical Care Nursing 7, 308-317.

Morse J \& Field P (1996) Qualitative Research. Sage, London.

Neary M (1997a) Defining the role of assessors, mentors and supervisors: part 1. Nursing Standard 15, 34-36.

Neary M (1997b) Defining the role of assessors, mentors and supervisors: part 2. Nursing Standard 15, 35-40.

Öhrling and Hallberg, 2000.

Öhrling K \& Hallberg IR (2000) Student nurses' lived experience of preceptorship. Part 1: in relation to learning. International Journal of Nursing Studies 37, 13-23.

Ormerod JA \& Murphy FA (1994) One step along the way: the introduction of supernumerary status for RGN students in Foresterhill College, Aberdeen. Nurse Education Today 14, 3037.

Parahoo K (1992a) Perceptions of supernumerary status. Nursing Standard 6, 37-40.

Parahoo K (1992b) Implementation of supernumerary status. Nursing Standard 6, 37-40.
Patton JG \& Cook LR (1994) Creative alliance between nursing service and education in times of economic constraint. Nursing Connections 7, 29-37.

Phillips T, Schostack J \& Tyler J (2000) Practice and Assessment in Nursing and Midwifery: Doing it for Real. Researching Professional Education Series no. 16. ENB, London.

Robinson N (1999) The use of focus group methodology - with selected examples from sexual health research. Journal of Advanced Nursing 29, 905-913.

Scholes J \& Endacott R (2002) Evaluation of the Effectiveness of Educational Preparation for Critical Care Nursing. ENB, London. Spouse J (2000) An impossible dream? Images of nursing held by pre-registration students and their effect on sustaining motivation to become nurses. Journal of Advanced Nursing 32, 730-739.

Watson R \& Norrie K (1997) Conference report. The Edinburgh University Nursing Society (EUNS) 2nd annual conference for final year students on the theme 'The supernumerary status of student nurses', held in the John McIntyre centre, University of Edinburgh, Edinburgh, Scotland, 18 February 1997. Journal of Advanced Nursing 26, 635-636.

White E (1993) A detailed study of the relationships between teaching, support, supervision, and role modelling for students in clinical areas within the context of Project 2000 courses. Research Highlights. English National Board, London.

Yassin T (1994) Exacerbation of a perennial problem? The theory practice gap and changes in nurse education. Professional Nurse 10, 183-187. 